\title{
Teaching Children with Learning Disabilities in the Mainstream Classes: The Challenges
}

\author{
Nilford Hove \\ Gauteng Department of Education, Johannesburg South District, Johannesburg, South Africa
}

Doi:10.5901/mjss.2014.v5n27p711

\begin{abstract}
The research was aimed at establishing the challenges that are being faced by mainstream class teachers in the teaching of children with learning disabilities in the Johannesburg South District schools. One hundred and seven educators were selected to respond to the questionnaire which was in the form of a Likert scale. The results indicated that indeed there are challenges that are being faced by the mainstream class teachers. These challenges among others include the lack of skills bases on the part of the teachers, class sizes, shortage of relevant instructional materials, and lack of support services as well as the unavailability of enough time for extra tuition. The study was carried out through the quantitative research design. Data were presented through the use of graphs and tables for easy reading and interpretation.
\end{abstract}

Keywords: Mainstream classes, Inclusive Education, Grouping, Learning disabilities, Curriculum, Instructional materials.

\section{Introduction}

Salamanca statement, (1994), proposes that the Inclusive education system should be responsive to the diverse needs of all learners and be accommodative of their different styles and language needs. Muthukrishna (2002) notes that when the democratic government of South Africa assumed power in 1994, it aimed at establishing a society based on the values of fundamental human rights, social, justice, freedom and equity. This ideology was informed by the need to treat all human beings as equal regardless of their ability or disability.

One would wonder whether the implementation of Inclusive education in South Africa is as smooth sailing as it should be. According to Hadebe (1993), the instructional demands of meeting the academic and behavioral needs of students with learning disabilities create a burden that decreases the teachers' ability to meet the academic and the social needs of other normal students. In the same vein, Polloway, Parton and Serna, (2008), note that students with special needs often require services and instructional support services because they are not dealing well with traditional methods and materials. This may have the implication that, giving the extra supports and services to students with learning disabilities in the mainstream classes impinges on the progress of the average and above average in those classes.

According to Vaughn, Bos and Schumm (2006), teachers must be very adept at instructional management if they are to create better learning opportunities in the class. Frederickson and Cline (2003), purport that competence in the classroom events are organized to enable or disable their participation. This is a call for teachers to give equal opportunities to all the students in their classes as well as using instructional methods that address the diverse needs of the said students. Teachers should use instructional methods that strengthen and compensate for deficits in perception comprehension, memory and retrieval. (Hallhan and Kauffman, 2009)

According to Sigamoney (1999), education in mainstream classes presupposes the provision of adequate support services to the needs of children with learning disabilities. Teachers need to understand the individual needs of each child with a learning disability in order to prepare relevant work for him or her. In that regard, teachers need to be knowledgeable of each type of disability in order to provide for the necessary supports and services. This is because remediation of the problems of learning in disabled children is a highly specialized subject area which demands specific Knowledge and skills from practitioners (Schaik 2000)

\section{Goals of the Study}

The study sought to establish if there are any challenges that are being faced by the mainstream class teachers in the Johannesburg South District Schools. This was on the backdrop of the policy of inclusivity embraced by the Government of South Africa, endorsed through the Education White paper 6 of 2001. 


\section{Design}

The research was conducted through the quantitative research design. According to Welman, Kruger and Mitchell (2005), the quantitative research design studies large numbers of randomly selected cases. The quantitative research takes the outsider's perspective and it keeps a detached, objective view of the facts and will keep the research process hypothetically free from bias (Welman et al, 2005). The Johannesburg South District covers a large area hence the choice of this design.

\section{Sample}

According to Cohen, Manion, Morison K (2007), the participants are chosen because they possess the particular characteristics or knowledge being sought. In this case, the sample consisted of 107 mainstream class teachers in the Johannesburg South District. The participants were randomly selected from the entire population of the Johannesburg South district schools.

\section{Instrumentation}

A Likert scale type of questionnaire was used in this study. "Researchers use questionnaires so that they can obtain information about the thoughts, attitudes, beliefs, attitudes, values, perceptions, personality and behavioral intentions of research participants," Johnson and Christensen, (2004: 164). This particular instrument was chosen because the researcher did not want to influence the outcomes of the study in as much as he intended to let the participants give their views freely.

\section{Procedure}

The researcher personally distributed the questionnaire to the selected participants. He visited schools of the selected participants after the normal working hours to avoid interfering with their daily schedules. In meeting the participants, the researcher had the opportunity to explain to them the purpose of the study. After three days of giving out the questionnaire, the researcher made a follow-up telephonically to remind the participants of the need to attend to the questions. After a further three days, the researcher went around collecting the completed questionnaires.

\section{Data Analysis}

Data were analyzed through the use of tables and graphs. The purpose was to make for easy reading and interpretation. After collecting all the data, the researcher grouped related data together for interpretation purposes.

\section{Data presentation}

\begin{tabular}{|c|c|c|}
\hline \multicolumn{3}{|l|}{$\mathrm{N}(107)$} \\
\hline Item & $\begin{array}{c}\% \\
\text { Agree }\end{array}$ & $\begin{array}{c}\% \\
\text { Disagree }\end{array}$ \\
\hline 1. All educators need new skills to function effectively in the teaching of children with learning disabilities. & 83 & 17 \\
\hline 2. Regular class teachers sacrifice their time in the afternoon helping their students with disabilities. & 38 & 62 \\
\hline 3. Students with learning disabilities in the mainstream classes receive individual tutoring within these classes. & 46 & 54 \\
\hline $\begin{array}{l}\text { 4. Teachers in the mainstream classes give students with learning disabilities work that is less in terms of } \\
\text { complexity. }\end{array}$ & 49 & 59 \\
\hline
\end{tabular}

\section{Discussion}

Asked on whether mainstream class teachers need new skills to function effectively, eighty three percent of the respondents agreed to this. The high percentage of those who indicated the need for new skills (83\%) could be an indicator that the educators need new skills to be more effective in the classes. The result shows some inadequacies that relate directly to teacher training. Purportedly, the advent of inclusive education came into effect when the majority of the current practicing teachers were already practicing. As such, they never had any training in special needs 
education/inclusive education hence they feel ill-prepared to manage these students in their classes.

The use of relevant instructional materials is crucial to the education of the child with learning disabilities. Sixty eight percent of the respondents said they do not use instructional materials that cater for children with learning disabilities. Instead they resort to using the general approach to teaching and instructional use to children with learning disabilities in their classes. There could be a reason to this status quo. Mercer and Mercer (2005:21) note that "some of the realities facing general education teachers include pressure to cover a lot of content, raise the performance level of learners, teach large groups and prepare for multiple classes.

Sixty two percent of the respondents said they don't give their students extra tuition in the afternoons. A plausible explanation could be that the teachers use the afternoons to prepare for the next day's work. However, this could also be indicative of the fact that the teachers do not find enough time during the school day to attend to students with learning disabilities given that the time-tables are loaded with no free periods during the school hours.

According to Mercer and Mercer (2001), the demands of the class may be so extensive that the teacher may overlook the difficulties of students with learning disabilities. The instructional demands of meeting the academic and behavioral needs of students with learning disabilities create an added burden that decreases their ability to meet the academic and the social needs of other normal students. From the research, fifty four percent of the respondents disagreed that they provide for individual tutoring in their classes. This could be due to the large number of students in the classes that they have to attend to.

Fifty one percent of the respondents indicated that they give their students the same tasks in terms of complexity regardless of their students' abilities or disabilities. In essence, students with learning disabilities would require work that is less in terms of complexity compared to the average and those above average.

\section{Conclusion}

The outcomes of the study indicated to a number of challenges. The challenges noted include among others, the lack of skills amongst teachers that enable them to function effectively in the mainstream classes. The instructional materials being used by the mainstream class teachers are those that are designed for students who are average and above average. Such materials do not take into consideration the operational levels of those with learning disabilities. This challenge is further compounded by the fact that the said teachers do not possess the skills to tailor the content to the needs of those with learning disabilities. Selection of the learning task is a critical instrumental decision. No matter how excellent the teaching procedures, instruction will not be effective if the task selected is inappropriate for the learner (Lewis and Doorlag, 1991).

The other challenges noted relate to the lack of time for extra tuition in the afternoons. Individual tutoring was also found out to be difficult to implement during the school day in the mainstream classes. Also, teachers are generally giving the same number of tasks to all the students in terms of complexity.

\section{Recommendations}

It was revealed from the research that mainstream class teachers in Johannesburg South district need to be equipped with the Skills to handle children with learning disabilities in their classes. A number of measures can be engaged in this regard. These measures border around in-service training, workshops at cluster and school levels, teacher training, curriculum and capacity building of the school management teams (SMTs) as well as the school based support teams.(SBST)

\subsection{In-service training}

The consideration for the in-service training programs is basically informed by the fact that the majority of the current practicing teachers never had any training, formal or informal, in issues to deal with special needs. These in-service programs will therefore help in helping the teachers understand the condition learning disability thereby increasing their awareness and appreciation of these students. The programs can be done by the universities involved in the teacher training programs in collaboration with the department of basic education (DBE). Teachers may be encouraged to take a module or two in inclusive education as a way of upgrading themselves 


\subsection{Workshops}

Workshops are a viable tool that can be effectively used to mitigate the challenges. Qualified personnel from the District Based Support team can be asked to hold workshops with teachers as a way of equipping them with the needed skills. This can be done at cluster level or school level. Such workshops are vital as they help the teachers to meaningfully interact with qualified personnel as they address the issues they face in their classes on a daily basis. The teachers will be able to bring practical examples of the challenges and in turn gain practical solutions to those challenges.

Work shopping of teachers should also extend to the school management teams and school based support teams. If this is properly done, teachers will be gaining in that they will have to turn to these bodies in case of any help with regards to individual students in their classes. It is important to note that despite harnessing the skills of inclusive teaching, workshops do help in enhancing positive attitudes towards children with learning disabilities.

\subsection{Practicum}

Since children with learning disabilities are almost certain to be found in every class, teacher training must entail an extensive program of learning in inclusive education. Student teachers must be compelled to write comprehensive reports about their engagements with children with learning disabilities while doing their practicum. In a way, this increases the student teachers' contact with such students thereby developing a deeper understanding of their needs.

\subsection{Instructional materials}

The use of appropriate instructional materials is very important in ensuring productive learning for students with learning disabilities. More often than not, these students need instructional materials that are stimulating enough to retain their attention. The provision of audio tapes and computer assisted instructions could be very helpful. The department of basic education could roll out a program that facilitates learning through computers at each and every school. This can be done holistically but with a bias towards students with learning disabilities. Relevant mobile charts should also be provided for the teachers to use.

\subsection{Extra tuition}

There is not enough time during the school day to be dedicated to the individual teaching of students with learning disabilities in the mainstream classes. This is because the class sizes are generally too large. School timetables must therefore be structured in such a way that there is an extra afternoon period. This afternoon period will specifically be serving the purpose of catching up on work that the students with learning disabilities would have struggled to cope with.

\subsection{Specialist teachers}

The Department of Basic Education may consider the deployment of a specialist teacher at every school in the district. Deployment of specialist teachers at cluster levels should be considered if there are not enough such teachers in the district. These specialist teachers will act as resource persons to all the other teachers. The specialist teachers will also be able to make follow ups on all the students with learning disabilities in the schools and advise teachers on methods that they can apply in their teaching.

\section{References}

Christensen, L.B; Johnson, B.R and Turner, L.A (2011) Research Methods, Design and Analysis, Boston: Allan and Bacon. Cohen. L; Manion.L; Morrison, K (2007), Research Methods in education, London: Routeledge

Engelbrecht, P; Green, L: Sigamoney, N and Engelbrecht, L (1999), Inclusive Education in Action In South Africa, Pretoria: J.L Van Schaick Publishers.

Frederickson, N and Chine, T (2003), Special Educational Needs, Inclusion and Diversity, London, Open University press

Hadebe, J.M, (1993) Development of special education in Zimbabwe. A report on special Development in post independence Zimbabwe, Harare: Ministry of education.

Hallahan, D.P Kauffman, J.M Pullen, P.C (2009) Exceptional learners. An Introduction to Special Education, Boston; Pearson Education, Inc.

Learner, J.W (2000), Learning Disabilities, Theory, Diagnosis and Teaching strategies, Boston: Houghton Miffin company. 
Lewis, R.B and Doorlag, D.H, (1991), Teaching special students in the mainstream, McMillan Publishing Company, New York.

Mercer, C.D and Mercer, A.R (2005), Teaching students with learning problems, New Jersey, Pearson Prentice Hall.

Muthukrishna, N (2002) Inclusive Education in a rural context in South Africa: Emergency policy and practices, International Journal of special Education, Volume 17, No.1.

Polloway, E.A; Patton, J.R and Serna, L (2008) Strategies for Teaching Learners with Special Needs, Pearson Prentice Hall, New Jersey.

Salamanca statement and Framework for action on special Needs Education (1994) Salamanca, Spain.

Sigamoney, M.N (2008), Curriculum 2005, A SPACE FOR ALL: An introduction to Inclusive Education, Western Cape National Book Publishers

Vaughn, S; Bos, S.C and Schumm, S.J (2006), Teaching Exceptional, Diverse and AT-Risk students In the General Education Classroom, Boston: Allyn and Bacon.

Welman F; Kruger; B and Mitchell B (2005) Research Methodology, Cape Town: Oxford University PRESS, South Africa (Pty) Ltd. 